\title{
Arglabin could target inflammasome-induced ARDS and cytokine storm associated with COVID-19
}

\author{
Azadeh Manayi ${ }^{1}$ - Seyed Mohammad Nabavi ${ }^{2} \cdot$ Maryam Khayatkashani $^{3} \cdot$ Solomon Habtemariam $^{4}$. \\ Hamid Reza Khayat Kashani ${ }^{5}$ (D)
}

Received: 2 August 2021 / Accepted: 8 October 2021 / Published online: 15 October 2021

(c) Crown 2021

\begin{abstract}
Arglabin (1(R),10(S)-epoxy-5(S),5(S),7(S)-guaia-3(4),1l(13)-dien-6,12-olide), is a natural sesquiterpene $\gamma$-lactone which was first isolated from Artemisia glabella. The compound has been shown to possess anti-inflammatory activity through inhibition of the NLR Family pyrin domain-containing 3 (NLRP3) inflammasome and production of proinflammatory cytokines including interleukin (IL)-1 $\beta$ and IL-18. A more hydrophilic derivative of the compound also exhibited antitumor activity in the breast, colon, ovarian, and lung cancer. Some other synthetic derivatives of the compound have also been synthesized with antitumor, cytotoxic, antibacterial, and antifungal activities. Since both NLRP3 inflammasome and cytokine storm are associated with the pathogenesis of COVID-19 and its lethality, compounds like arglabin might have therapeutic potential to attenuate the inflammasome-induced acute respiratory distress syndrome and/or the cytokine storm associated with COVID-19.
\end{abstract}

Keywords Artemisia $\cdot$ Asteraceae $\cdot$ Arglabin $\cdot$ Corona virus $\cdot$ COVID-19 $\cdot$ Anti-inflammation

\section{Introduction}

Since the World Health Organisation (WHO) announced the COVID-19 pandemic on January 30th 2020, the global scientific interest in coronaviruses have increased exponentially [1]. Based on genotype and serological properties, the positive-sense single-stranded ribonucleic acid (+SS-RNA) viruses that infect both human and animals are subdivided into four genera (alpha, beta, gamma, and delta). In the past two decades, the three epidemics caused by beta coronaviruses (CoVs) were SARS in 2002-2003, MERS in 2012 and

Hamid Reza Khayat Kashani

1 Faculty of Pharmacy, Medicinal Plants Research Center, Tehran University of Medical Sciences, Tehran, Iran

2 Applied Biotechnology Research Center, Baqiyatallah University of Medical Sciences, Tehran, Iran

3 School of Iranian Traditional Medicine, Tehran University of Medical Sciences, Tehran, Iran

4 Pharmacognosy Research Laboratories and Herbal Analysis Services, University of Greenwich, Central Avenue, Chatham-Maritime, UK

5 Imam Hossein Hospital, Shahid Beheshti University of Medical Sciences, Madani Street, Tehran, Iran
COVID-19, first identified in 2019 [2]. At present, there is no effective antiviral therapy against coronaviruses. However, some synthetic compounds with promising effects have been on the spotlight and include chloroquine phosphate, hydroxychloroquine, or new antiviral medicines like lopinavir, remdesivir, and arbidol [3].

Plants contain complex matrices of phytochemicals that induce biological activity either individually or often in a synergistic manner. These compounds may protect plants against fungi and insects' infections, or from UV radiation, changes in salinity or temperature $[4,5]$. For thousands of years, potential therapeutic agents for human diseases have been solely provided by nature. In this connection, a significant proportion of our modern medicine today traces their origin to natural products. With respect to drug development, traditional herbal medicines and purified natural compounds can guide us to discover novel antivirus medicines [6]. New drugs with desired activity may also be designed based on the structures of natural product scaffolds. Indeed, between 1981 and 2014, 50\% of all approved medicines were derived from or mimicked a natural compound [7]. Besides, during the current pandemic of COVID-19, complementary and traditional therapeutics have been applied in many countries in conjunction with conventional medicines $[6,8,9]$. The 
genus Artemisia L., belongs to the Asteraceae (Compositae) family which comprises over 400 species distributed mainly in the temperate zone of Europe, Asia and North America [10]. Among them, Artemisia апnи a have been traditionally used for the treatment of fever, malaria, and respiratory tract infections. In a small clinical study, administration of the artemisinin (active component of Artemisia annua) derivative, artesunate, resulted in shorter duration of COVID-19 symptoms [11]. Some trials using Artemisia spp. or Artemisia products have also been registered for COVID-19 [12].

The cytosolic pattern recognition receptors in COVID19 infection can activate the inflammasome in response to viroporin $\mathrm{E}$ and $3 \mathrm{~A}$ of Coronaviruses. Until now, some bioactive small molecules have been reported to down-regulate inflammasome. Among them, arglabin seems to have the potential for attenuation of inflammasome-induced ARDS and subsequent cytokine storm. Therefore, conducting clinical trials to evaluate the efficacy and safety of arglabin in the destructive inflammation cascade of COVID-19 is needed. The present communication discusses the chemical and biological features of arglabin to highlight the possible underlying mechanisms of action.

\section{Chemical properties of arglabin}

Sesquiterpenes lactones with diverse chemical structures are abundantly found in plants of the Asteraceae family of which the genus Artemisia is exemplary [13]. These compounds exhibit potential pharmacological activities like antihelminthic, antitumor, and antishistosomal effects [14]. Arglabin (molecular formula, $\mathrm{C}_{15} \mathrm{H}_{18} \mathrm{O}_{3}$ ) is a colorless crystalline compound with chemical structure constructed from the bicyclo [5.3.0] decane skeleton. The compound belongs to the guaianolides sesquiterpenes subclass and was first isolated in early $1980 \mathrm{~s}$ from Artemisia glabella which is endemic to Kazakhsta [15]. Arglabin is also isolated from another related species, Artemisia myriantha which is a wellknown Chinese medicinal herb [16]. In this class of sesquiterpenes, a $\gamma$-lactone ring is inserted at the position of $\mathrm{C}-6$ and C-7 or C-7 and C-8 (Fig. 1). Five contiguous stereo centers are available in this 5,7,5-tricyclic ring system in which two of the five-membered rings are trans-annulated [14]. In addition, the compound has an epoxy group and an olefinic double bond in the cycle. With melting point of $101-104{ }^{\circ} \mathrm{C}$ and $\mathrm{a}_{[\mathrm{D}]}+45^{\circ}$ (c 0,3 ; chloroform), the compound is insoluble in water [17]. The poor solubility of arglabin in water negatively influence the bioavailability and consequently the pharmacological activity of the compound. Structural modification of the compound to enhance water solubility should thus be considered as a rational approach in improving its bioavailability. For instance, a structural complex formation between arglabin and polyvinylpyrrolidone and disodium

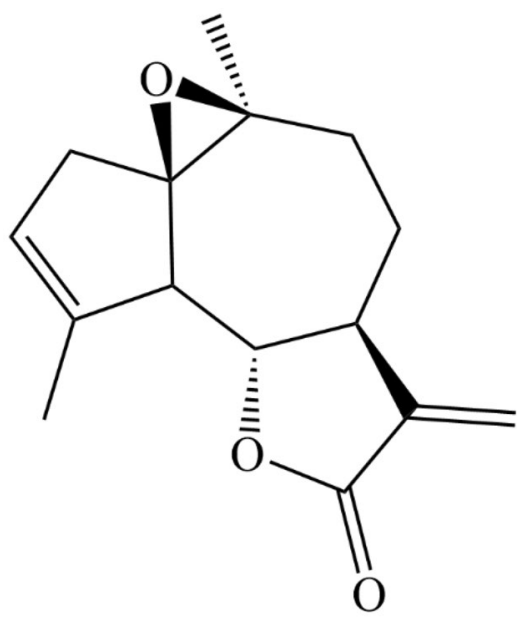

Fig. 1 Chemical structure of arglabin

salt of glycyrrhizic acid increased the water solubility of the compound by more than four times [18].

Over 70 new polyfunctional derivatives of arglabin have been synthesized by cyclopropantation, amination, phosphorylation, halogenations, and oxidation of the compound. All derivatives of arglabin also have some degree of biological activity. The maximum cytotoxic and antitumor activity was observed for diepoxy, amino, and phosphorus derivatives against Gueri carcinoma, P-388 leukemia, sarcoma-45, and Artemia salina larvae. The data indicated that the bromo and chloro moiety at 3 and 4 positions strongly increase the cytotoxic activity of the compound. Diethyl amino and methyl iodide dimethyl amino derivatives also exhibited antitumor, cytotoxic, antifungal and antimicrobial activities [19].

\section{Biological activities of arglabin}

The structurally modified and more water-soluble arglabin derivative with a dimethylamino hydrochloride (DMA) group attached to the $\mathrm{C}-13$ carbohydride moiety (arglabin-DMA) was approved for cancer treatment in 1996 in Kazakhstan for breast, colon, ovarian, and lung cancers. According to the result of one study, arglabin-DMA displayed antitumor activity by preventing farnesylation of cell proteins through direct inhibition of the enzyme, farnesyltransferase [20]. The expression of H-Ras oncoproteins were also suppressed by arglabin in patients suffering from breast cancer [21]. Moreover, the compound suppressed the synthesis of IFN- $\gamma$, IL-2, and anti-inflammatory cytokine such as IL-4, TNF- $\alpha$, and IL- $1 \beta$ in patients with breast cancer [19]. Treatment of oral squamous cancer cells with arglabin arrested cell growth and induced apoptosis in vitro. Apoptotic parameters like bleb formation, fragmentation of cancer cell, and chromosomal condensation increased after 
treatment of the cells with arglabin. The compound induced apoptosis through increasing the production of reactive oxygen species (ROS) in cells resulting in the generation of pore openings in the mitochondrial membranes [22].

When arglabin was administered intraperitoneally in ApoE2.Ki mice fed with high fat diet, inflammation, plasma lipids, antibodies directed against oxidized low-density lipoprotein (oxLDL), and IL- $1 \beta$ plasma level along with development of atherosclerosis were reduced [23]. The orientation of tissue macrophage into anti-inflammatory phenotype was also reported for the compound. It also inhibited IL- $1 \beta$ and IL-18 in cultured C57Bl/6, NLRP3+/+ mouse peritoneal macrophages in a concertation-dependent manner, while production of both cytokines were not affected in the C57B1/6, NLRP3-/- mouse peritoneal macrophages. In addition, arglabin inhibited NLRP3 inflammasome in the macrophages treated with cholesterol crystals. Therefore, it was suggested that the compound might prevent the development of atherosclerosis in a murine model through inhibition of the NLRP3 inflammasome activity. The compound also primarily increased degradation of NLRP3 and pro-IL-1 $\beta$ by inducing autophagy in macrophages [23]. The derivative of the compound, 11, 13-dihydro-13-dimethylamino arglabin hydrochloride, showed antioxidant and antiproliferative activity in different models of inflammation induced by carrageenan, histamine, and formalin and on proliferative inflammation model accompanying cotton-pellet granuloma [24]. Furthermore, arglabin showed anti-inflammatory activity in chronic endometritis model by promoting regeneration processes in endometrium [19].

Five sesquiterpene lactones with a-methylene- $\gamma$-lactone moieties including arglabin inhibited $\mathrm{Ca}^{2+}$ mobilization and the depletion of intracellular level of reduced glutathione (GSH) in Jurkat T cells, and blocked ERK1/2 phosphorylation in dose dependent manner. These suggest the immunomodulatory and anti-inflammatory properties of arglabin [25]. In the cyclophosphane immunosuppressive model, arglabin showed high immunomodulatory effect by increasing the number of $\mathrm{T}$ lymphocytes, enlarging theophylline sensitive T-lymphocytes and B-lymphocytes, theophylline resistant T-lymphocytes, strengthening cells migration from thymus medullary substance, and activating processes of phagocytosis in the spleen [19]. The production of IL-1 $\beta$ was also reduced in the Langerhans islets isolated from ApoE2.Ki mice in the presence of arglabin. This inhibitory effect was specifically associated with NLRP3 inflammasome since the production of IL- $1 \beta$ was abolished in isolated Langerhans islet from NLRP-/- mice. In INS-1 cells treated with arglabin, the level of Bcl-2 increased while susceptibility of cells to apoptosis was reduced [26]. The expression of autophagic markers, Beclin 1 and LC3-II, were also dose-dependently increased by arglabin. Therefore, the antiinflammatory effect of the compound was dependent on NLRP3 and apoptosis; while it increases autophagy in cultured INS-1 indicating the promotion of cell survival by arglabin in these cells [26]. In addition, the compound inhibited influenza virus type $\mathrm{A}$ in vitro at a dose of $100 \mu \mathrm{M}$ [19].

\section{Cytokine storm in COVID-19}

Fever, cough, fatigue, myalgia, and dyspnea are the initial symptoms of COVID-19 while acute respiratory syndrome (ARDS) or multiple organ failure may develop in the later stages of the disease [27]. All the latest available evidence suggest that cytokine storm is the major cause for the severity and death from COVID-19 [28]. In cases of severe COVID-19, excessive immune response which is known as cytokine storm is triggered by the infection and characterized by high-level of immune cells activation and production of inflammatory cytokines and other chemical mediators [29]. Nod-like receptor family, NLRP3inflammasome and cytokine storm are significantly associated with the lethality of COVID-19 [30, 31]. The cytokine storm in COVID-19 patients is also related to severe lymphopenia, thrombosis, and infiltration of mononuclear cell in organs [32]. In the lung autopsy tissues of COVID-19 patients, high levels of inflammatory cytokines like IL- 6 and IL- $1 \beta$ were detected $[28,33]$.

To recognize pathogens like viral infection, the innate immune system need to be activated by a key player NLRP3 inflammasome [34]. Three ion channel proteins including E, open reading frame $3 \mathrm{a}(\mathrm{ORF} 3 \mathrm{a})$, and ORF8a are encoded by SARS-CoV genes and E and ORF3a are required for both replication and virulence. The viroporin $\mathrm{E}$ and ORF3a can act as ion channels and activate NLRP3 inflammasome. In addition, ORF3 independently to its ion-channel role promotes NLRP3 inflammasome by modulation of ubiquitination of inflammasome adaptor protein (caspase-recruitment domain: ASC) and production of pro-IL- $1 \beta$ through activation of nuclear factor kappa-light-chain-enhancer of activated B cells (NF- $\kappa B$ ). Besides, inflammasome receptors interact with adaptor protein ASC (through their domains i.e., CARD and PYD) and then increase the recruitment of pro-caspase- 1 and eventually activate caspase- 1 . The activated caspase- 1 can cleave the immature proinflammatory cytokines and also Gasdermin-D and consequently triggers the cytokine storm and pyroptosis [35-37].

\section{Discussion}

According to earlier studies, arglabin showed antitumor activity and has been prescribed as an anticancer medicine in Kazakhstan. The compound showed anti-inflammatory activity by inhibition of key inflammatory transcription 
factor like NLRP3 inflammasome. Arglabin also suppressed the synthesis of IFN- $\gamma$, IL-2, IL- $1 \beta$, IL-18, and TNF- $\alpha$ which were shown to be associated with morbidity in COVID-19. Toxicological study has not shown any teratogenic, embryotoxic, and mutagenic properties [19]. No morphological change in composition of peripheral blood and bone marrow were reported and it did not affect the functional status of liver, kidney, respiratory and cardiovascular systems. Besides, no local irritation was reported by administration of the drug through intravenous, abdomen, intramuscular, or subcutaneous injections. Arglabin caused no allergic or pyrogenic properties [19]. Since the safety of arglabin was only indicated in some studies, further studies are needed to clarify the toxicology profile of the compound. On the other hand, this compound along with other medications can be considered as a potential therapy for patients suffering from severe COVID-19, because it inhibits factors resulting in cytokine storm, which greatly complicate the disease.

Acknowledgements Not applicable.

Author contributions AM, HRKK and MK helped in writing the manuscript; SMN, AM and HRKK conceived the idea, helped in designing the study and MK and SH edited the manuscript.

Funding Not applicable.

\section{Declarations}

Conflict of interest The authors declare that they have no competing interests.

Ethical approval Not applicable.

Consent to publish Not applicable.

\section{References}

1. Sohrabi C, Alsafi Z, O'Neill N et al (2020) World Health Organization declares global emergency: a review of the 2019 novel coronavirus (COVID-19). Int J Surg 76:71-76

2. Pal M, Berhanu G, Desalegn C, Kandi V (2020) Severe Acute Respiratory Syndrome Coronavirus-2 (SARS-CoV-2): an update. Cureus 12:e7423

3. Xu XW, Wu XX, Jiang XG et al (2020) Clinical findings in a group of patients infected with the 2019 novel coronavirus (SARS-Cov-2) outside of Wuhan, China: retrospective case series. BMJ 368:m606

4. Saeidnia S, Manayi A, Gohari AR, Abdollahi M (2014) The story of beta-sitosterol-a review. Eur J Med Plants 4:590-609

5. Saeidnia S, Asili J, Manayi A et al (2017) Bioactive sesquiterpene lactone from Artemisia santolina. Boletín Latinoamericano y del Caribe de Plantas Medicinales y Aromáticas 16:570-577

6. Kapepula PM, Kabengele JK, Kingombe M et al (2020) Artemisia spp. derivatives for COVID-19 treatment: anecdotal use, political hype, treatment potential, challenges, and road map to randomized clinical trials. Am J Trop Med Hyg 103:960-964

7. Newman DJ, Cragg GM (2016) Natural products as sources of new drugs from 1981 to 2014. J Nat Prod 79:629-661

8. Liu C-x (2020) Pay attention to situation of SARS-CoV-2 and TCM advantages in treatment of novel coronavirus infection. Chin Herb Med 12:97-103

9. Ren J-1, Zhang A-H, Wang X-J (2020) Traditional Chinese medicine for COVID-19 treatment. Pharmacol Res 155:104743

10. Mozaffarian V (1996) A dictionary of Iranian plant names, Farhang Moaser. Iran, Tehran, pp 542-544

11. Cheong DH, Tan WD, Wong WF, Tran T (2020) Anti-malarial drug, artemisinin and its derivatives for the treatment of respiratory diseases. Pharmacol Res 158:104901

12. Orege JI, Adeyemi SB, Tiamiyu BB, Akinyemi TO, Ibrahim YA, Orege OB (2021) Artemisia and Artemisia-based products for COVID-19 management: current state and future perspective. Adv Tradit Med. https://doi.org/10.1007/s13596-021-00576-5

13. Ivanescu B, Miron A, Corciova A (2015) Sesquiterpene lactones from Artemisia genus: biological activities and methods of analysis. J Anal Methods Chem. https://doi.org/10.1155/2015/ 247685

14. Lone SH, Bhat KA, Khuroo MA (2015) Arglabin: from isolation to antitumor evaluation. Chemico-Biol Interact 240:180-198

15. Shaikenov T, Adekenov S, Belyaev N, Zakiryanova G (1997) Mechanism of action of the sesquiterpene from Artemisia glabella 'arglabin'in transformed tumor cells. Arglabin. Its structure properties and usage. Economy Printing, Portsmouth, pp 21-31

16. Bottex-Gauthier C, Vidal D, Picot F, Potier P, Menichini F, Appendino G (1993) In vitro biological activities of arglabin, a sesquiterpene lactone from the Chinese herb Artemisia myriantha Wall. (Asteraceae). Biotechnol Ther 4:77-98

17. Adekenov SM, Mukhametzhanov MN, Kagarlitskii AD, Kupriyanov AN (1982) Arglabin-a new sesquiterpene lactone from Artemisia glabella. Chem Nat Compd 18:623-624

18. Adekenov S, Zhabayeva A, Baisarov G (2020) Water-soluble substances of arglabin. Eurasian Chem Technol J 22:205-211

19. Adekenov S (2016) Chemical modification of arglabin and biological activity of its new derivatives. Fitoterapia 110:196-205

20. Shaikenov TE, Adekenov SM, Williams RM et al (2001) Arglabin-DMA, a plant derived sesquiterpene, inhibits farnesyltransferase. Oncol Rep 8:173-182

21. Adekenov S, Zhumakayeva A, Perminov V, Bekmanov B, Rakhimov K (2020) Neoadjuvant therapy with drug arglabin for breast cancer with expression of H-Ras oncoproteins. Asian Pac J Cancer Prev 21:3441-3447

22. He W, Lai R, Lin Q, Huang Y, Wang L (2018) Arglabin is a plant sesquiterpene lactone that exerts potent anticancer effects on human oral squamous cancer cells via mitochondrial apoptosis and downregulation of the mTOR/PI3K/Akt signaling pathway to inhibit tumor growth in vivo. J Balk Union Oncol 23:1679-1685

23. Abderrazak A, Couchie D, Mahmood D et al (2014) 0383: antiinflammatory and anti-atherogenic effects of the inflammasome NLRP3 inhibitor, arglabin, in ApoE2Ki mice fed a high fat diet. Arch Cardiovasc Dis Suppl 6:6-7

24. Abil'daeva A, Pak RN, Kulyiasov AT, Adekenov SM (2004) [Anti-inflammatory effect of arglabin and 11,13-dihydro13-dimethylaminoarglabin hydrochloride]. Eksp Klin Farmakol 67:37-39

25. Schepetkin IA, Kirpotina LN, Mitchell PT et al (2018) The natural sesquiterpene lactones arglabin, grosheimin, agracin, parthenolide, and estafiatin inhibit $\mathrm{T}$ cell receptor (TCR) activation. Phytochemistry 146:36-46

26. Abderrazak A, El Hadri K, Bosc E et al (2016) Inhibition of the inflammasome NLRP3 by arglabin attenuates inflammation, protects pancreatic $\beta$-cells from apoptosis, and prevents type 2 
diabetes mellitus development in ApoE2Ki mice on a chronic high-fat diet. J Pharmacol Exp Ther 357:487-494

27. Hu B, Huang S, Yin L (2021) The cytokine storm and COVID-19. J Med Virol 93:250-256

28. Huang C, Wang Y, Li X et al (2020) Clinical features of patients infected with 2019 novel coronavirus in Wuhan, China. The Lancet 395:497-506

29. Teijaro JR, Walsh KB, Rice S, Rosen H, Oldstone MB (2014) Mapping the innate signaling cascade essential for cytokine storm during influenza virus infection. Proc Natl Acad Sci 111:3799-3804

30. Sendler M, van den Brandt C, Glaubitz J et al (2020) NLRP3 inflammasome regulates development of systemic inflammatory response and compensatory anti-inflammatory response syndromes in mice with acute pancreatitis. Gastroenterology 158, 253-269. e214

31. Lin L, Xu L, Lv W et al (2019) An NLRP3 inflammasome-triggered cytokine storm contributes to streptococcal toxic shock-like syndrome (STSLS). PLoS Pathog 15:e1007795

32. Merad M, Martin JC (2020) Pathological inflammation in patients with COVID-19: a key role for monocytes and macrophages. Nat Rev Immunol 20:355-362
33. Zhu N, Zhang D, Wang W et al (2020) A novel coronavirus from patients with pneumonia in China, 2019. N Engl J Med 382:727-773

34. Zhao C, Zhao W (2020) NLRP3 inflammasome - a key player in antiviral responses. Front Immunol 11:211

35. de Rivero Vaccari JC, Dietrich WD, Keane RW, de Rivero Vaccari JP (2020) The inflammasome in times of COVID-19. Front Immunol 11:2474

36. Freeman TL, Swartz TH (2020) Targeting the NLRP3 inflammasome in severe COVID-19. Front Immunol 11:1518

37. Saeedi-Boroujeni A, Mahmoudian-Sani M-R, Nashibi R, Houshmandfar S, Tahmaseby Gandomkari S, Khodadadi A (2021) Tranilast: a potential anti-Inflammatory and NLRP3 inflammasome inhibitor drug for COVID-19. Immunopharmacol Immunotoxicol $43: 247-258$

Publisher's Note Springer Nature remains neutral with regard to jurisdictional claims in published maps and institutional affiliations. 